\title{
الكشف عن اللاتغير في الاختبار التقييهي لمهارات الرياضيات لطلبة الصف الثالث الأساسي عبر مديريات التربية في الأردن

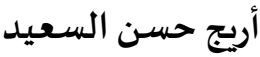 \\ مديرية التربية والتعليم لواء بني عبيد- إببد- الأردن \\ areej_alsaid@yahoo.com
}

\section{نضيال كمال الشريفين}

أستاذ دكتور في قسم علم النفس الإرشادي والتربوي- كلية التربية- جامعة اليرموك- الأردن

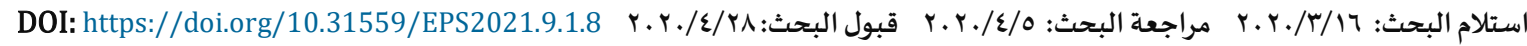

هدفت هذه الدراسة للكشف عن اللاتغير في الاختبار التقييمي للصف الثالث الأساسي في الأردن عبر متغير مديريات التربية والتعليم (عددها 0ـ مديرية). ولتحقيق ذلك تم استخدام المنهج الوصفي التحليلي في تحليل نتائج الطلبة على الاختبار الذين شاركوا في الاختبار للعام

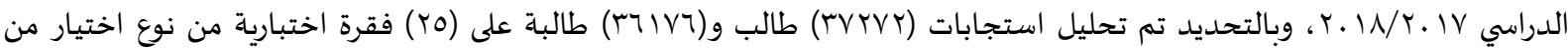

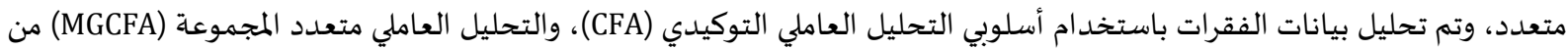
خلال البرنامج الإحصيائي (Mplus v8.4)، وللحكم على ملاءمة البناء العاملي للاختبار تم استخدام خمس مؤشرات حسن المطابقة وهي:

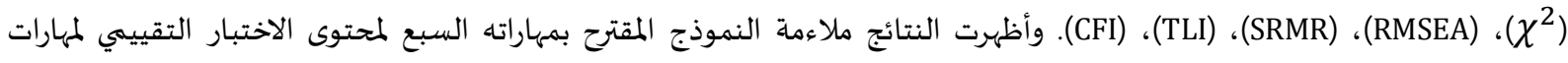

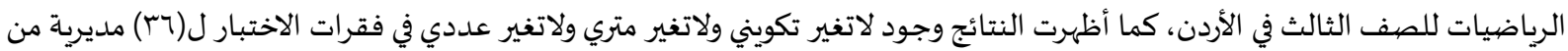

الكلمات المفتاحية: اللاتغير في القياس؛ الاختبار التقييمي لمهارات الرياضيات؛ مؤشرات حسن المطابقة؛ التحليل العاملي التوكيدي.

تطورت طرق تصميم الاختبارات والمقاييس وتحليل فقراتها، فالقياس النفسي والتربوي في تقدم مستمر، ومن أشهر النظريات المستخدمة النظرية الكلاسيكية للقياس (CTT) التي اختصت في بناء أنواع مختلفة من الاختبارات والمقاييس، إلا أها لم تتغلب على مختلف

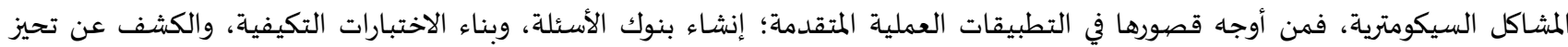
الفقرات (علام، ه . ب)، واختلاف معالم الفقرات باختلاف عينة الأفراد المستخدمة في استخراج هذه المعالم، كما أن النظرية الكلاسيكية لا تزودنا

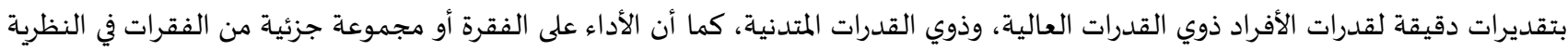
الكلاسيكية لا يقدم معلومات كافية عن مستوى أداء الفرد، بالإضافة إلى أن مفهوم الثبات في النظرية الكلاسيكية يقوم على أساس إمكانية تطوير

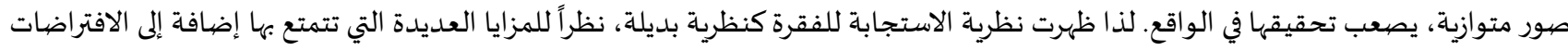
القوية التي اعتمدت عليها، والتي يفترض من خلالها تلافي عيوب النظرية الكلاسيكية ومنها مشكلة العدالة في التوزيع والتماثل واللاتغير (الشريفين، 
ا. أحادية البعد Undimensionality: تفترض النظرية الحديثة أن هناك سمة أساسية واحدة تفسر أداء المفحوص على الاختبار، وتنتج عنها النماذج أحادية البعد، أما في حالة افتراض وجود أكثر من سمة واحدة تفسر أداء المفحوص فالنماذج المنبثقة تسمى النماذج متعددة الأبعاد،

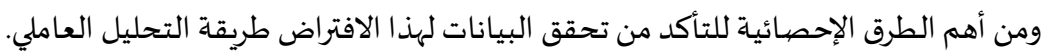

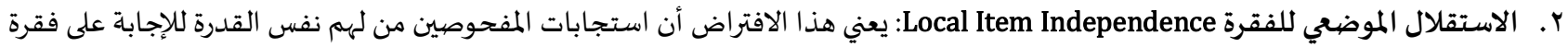

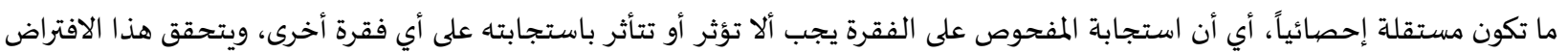
فقط في حالة الاختبار أحادي البعد. r. منحنى خصيائص الفقرة Item Characteristic Curve (ICC): هو اقتران تراكمي تصاعدي يصف العلاقة بين قدرة المفحوص وتحصيله على الاختبار.

ع. عدم السرعة Non- speediness: تفترض النظرية الحديثة أن عامل السرعة لا يؤثر على استجابات المفحوص على الفقرات.

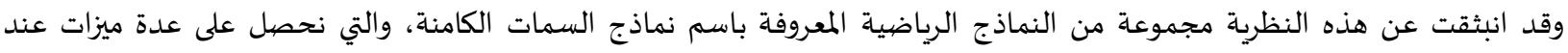

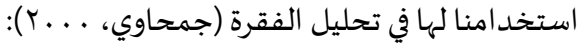
1. فقرات ذات خصائص سيكومترية متحررة من خصائص المفحوصين. r. خصائص المفحوصين متحررة من خصائص الفقرات التي تم الاستجابة عليها.

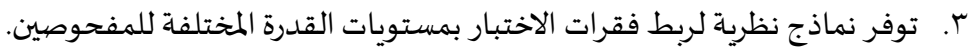
ع. نماذج مبنية على افتراضات يمكن الدفاع عنها.

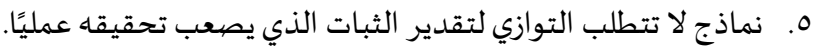

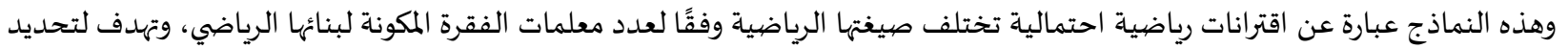

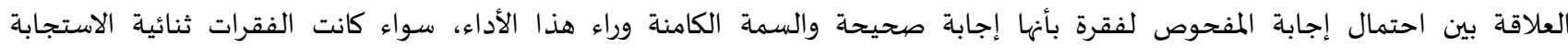
(Dichotomous response) (Hambelton, (Swaminathan وسيتم التركيز في هذه الدراسة على نماذج الفقرات ثنائية الاستجابة التي أوردها هامبلتون وسوامينثان وروجرز)

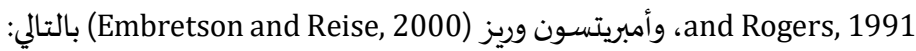
ا. النموذج اللوجستي أحادي المعلمة (One Parameter Logistic Model-1PLM). r. النموذج اللوجستي ثنائي المعلمة (Two Parameter Logistic Model-2PLM). r. موأخيرًا، النموذج اللوجستي ثلاثي المعلمة (Three Parameter Logistic Model-3PLM). وتستخدم هذه النماذج في بناء وتطوير المقاييس والاختبارات التي يمكن من خلالها الحصول على المعائل المؤشرات الإحصيائية للفقرة المتحررة من خصائص المفحوصين، وصعوبة فقرات المقياس، وهذا هو مفهوم خاصية اللاتغير في تقدير معلمات الفقرات بين مختلف المفحوصين، التي وصفها فينش (Finch, 2014) على أهها الحالة التي تقيس فيها أداة القياس السمة المتأصلة بنفس الطريقة لمجموعات موفات مختلفة من سياقات أو ثقافات أو أزمنة

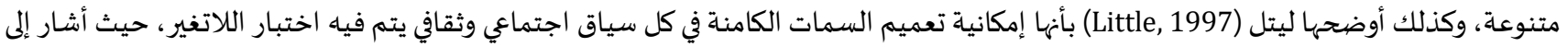

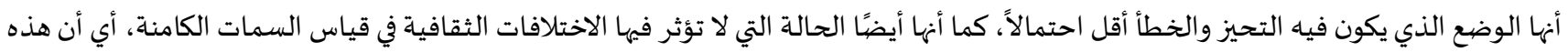

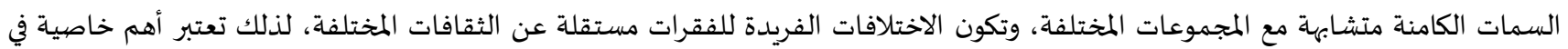
نظرية استجابة الفقرة (Lord, 1980)،

ومع تركيز علم النفس التربوي على دراسـة السلوك البشري الناتج عن السمات الكامنة التي لا يمكن ملاحظتها، وإنما الاستدلال عليها من استجابات المفحوصين على الأدوات المبنية لقياس تلك السمات، ظهرت الكئير من من النماذج الإحصائية والبرامج الحاسوبية لتحقيق هذا الهدف، ومن

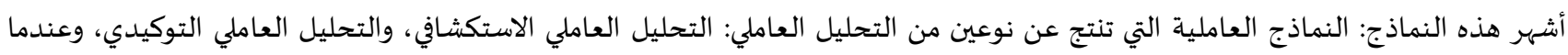

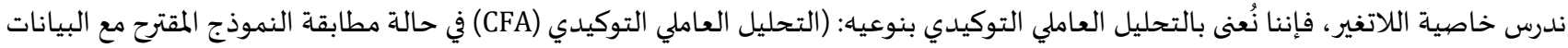

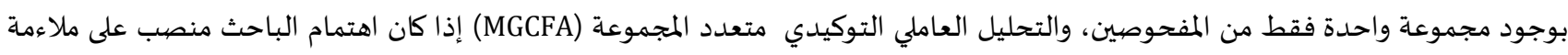
النموذج المقترح لبيانات ناتجة من عدة مجموعات مختلفة من المفحوصين) (Billiet, 2003; Jöreskog, 1971).

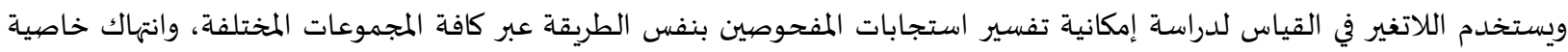
اللاتغير يحول دون تفسير البيانات تفسيرًا ذا معنى، لذلك يتم الاهتمام بتحقق الاختبارات والمقاييس النفسية لخاصية اللاتغير بشكل متزايد

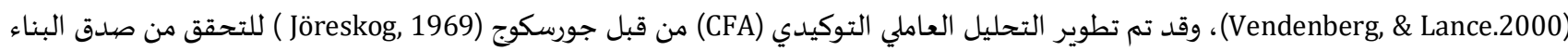

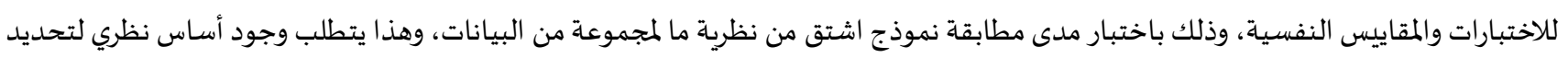

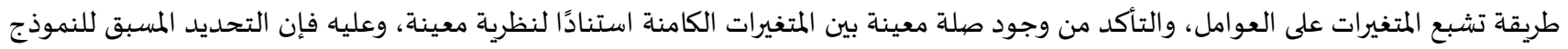


يسمح للمتغيرات بالتشبع على العوامل المحددة بحرية دون غيرها ثم يتم تقويم النموذج لتحديد دقة مطابقته للبيانات المستخدمة من خلال مؤشرات إحصائية تسمى مؤشرات حسن المطابقة، تساعد الباحث على تحديد مدى جودة النموذج المقترح عن طريق مقارنته بنموذج آخر (Gadelrab, 2004)

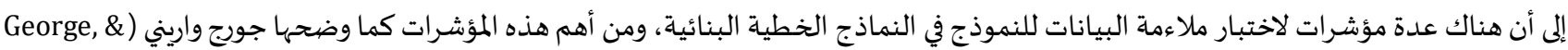
2002 . Irini. ولاتن وكارول وجرين (Lattin, Carrol, \& Green. 2003): مؤشر مربع كاي، ومؤشر الملاءمة المقارن، ومؤشر تاكر لويس، وجذر متوسط خطأ التقريب، وجذر متوسط البواقي المعيارية، وفي حالة استخدام التحليل العاملي التوكيدي، والتحليل العاملي التوكيدي متعدد المجموعاة فإنانه يتم الاعتماد على مجموعة من مؤشرات حسن المطابقة يتم الحكم عليها وفق علامة قطع متفق علهيا في الأدب النظري. ويبين جدول (1) المؤشرات وعلامة

القطع لكل منها:

جدول (1): مؤشرات جودة المطابقة وعلامة القطع لكل منها

\begin{tabular}{|c|c|c|c|}
\hline المصددر & علامة القطع & الرمز & اسم المؤشر \\
\hline & دال إحصائيًا & $\chi^{2}$ & كاي تربيع chi-square \\
\hline Cangur \& Ercan, 2015 & $0-1$ & $\chi^{2} / d f$ & كاي تربيع/ درجات الحرية \\
\hline $\begin{array}{l}\text { Hair, Anderson, Tatham, \& } \\
\text { Bentler, } 1995\end{array}$ & 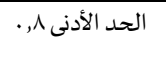 & CFI & مؤشر الملاءمة المقارن Comparative Fit Index \\
\hline Hu, \& Bentler, 1999 & 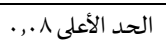 & RMSEA & جذر متوسط خطأ التقريب Root Mean Square Error of Approximation \\
\hline Hu, \& Bentler, 1999 & 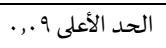 & SRMR & جذر متوسط البواقي المعيارية Standardized Root Mean Residual \\
\hline Bentler, 1990 & 1 1.. & TLI & مuؤشر تاكر لويس Tucker-Lewis Index \\
\hline
\end{tabular}

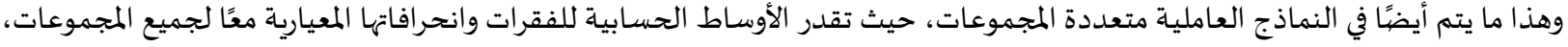

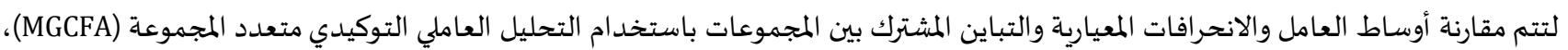
وفي حالة الاختبار التقييمي لمهارات الرياضيات للصف الثالث الأساسي موضوع الدراسة فهو اختبار ذات فقرات ثنائية الاستجاباة، لذلك سيتم بداية

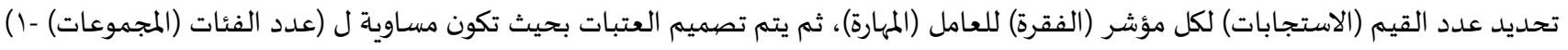
(Muthén and Christoffersson, 1981) خاصية اللاتغير بأنواعاء الثلاث بمقارنة المؤشرات الإحصائية لحسن المطابقة الفارقة بمقارنة نموذجين ببعضهما (التكويني، والمتري، والعددي)، والحكم عليها وفق علامة قطع متفق عليها في الأدب النظري، ويبين الجدول (r) المؤشرات وعلامة القطع لكل منها.

جدول (r): مؤشرات المطابقة الفارقة لمقارنة نماذج اللاتغير وعلامة القطع لكلل منها

\begin{tabular}{|c|c|c|c|}
\hline ا لمصدر & علامة القطع & 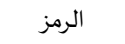 & اسم المؤشر \\
\hline Tuker \& Lewis, 1973 & غير دالة إحصائيًا & $\Delta \chi^{2}$ & مربع كاي الفارقة \\
\hline Tuker \& Lewis, 1973 & الحد الأعلى ا .,.. & $\Delta \mathrm{CFI}$ & مقارنات مؤشر الملاءمة المقارن \\
\hline Tuker \& Lewis, 1973 & الحد الأعلى 0 ., . & $\Delta \mathrm{TLI}$ & مقارنات مؤشر تاكر لويس \\
\hline Tuker \& Lewis, 1973 & الحد الأعلى ؟ .,. & $\Delta$ SRMR & مقارنات الجذر المعياري لمتوسط البواقي \\
\hline Chen, 2007 & الحد الأعلى 10 ., . . & $\triangle$ RMSEA & مقارنات جذر متوسط خطأ التقريب \\
\hline
\end{tabular}

وهنا يميز الباحثون بين ثلاثة مستويات لقياس اللاتغير:

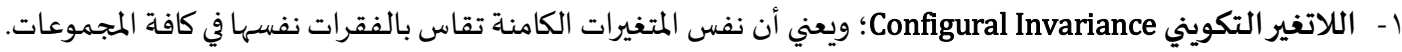
ץ- اللاتغير المتري Metric Invariance؛ فيعني أن المتغيرات الكامنة تقاس بنفس الفقرات لكافة المجموعات ومعاملات تحميل الفقرات متشابهة

$$
\text { عبر المجموعات. }
$$

ب- اللاتغير العددي Scalar Invariance؛ فإنه يهتم بتحقق ما سبق بالإضافة لتساوي معاملات تحميل العامل ومؤشر تقاطعات العامل عبر

المجموعات (Vandenberg and Lance, 2000).

Millsap, ( ولضمان قابلية المقارنة لأوساط العامل، يجب تحقيق خاصية اللاتغير على معاملات التحميل وتقاطعات القياس، أي اللاتغير العددي

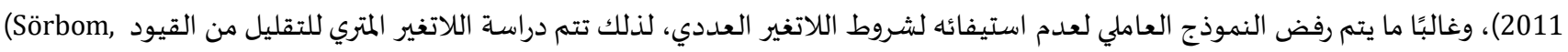
(1989، وللتحقق من خاصية اللاتغير في القياس للمقاييس واسعة النطاق المطبقة لتحقيق مجموعة متنوعة من الأهداف: مثل مقارنات تحصيل

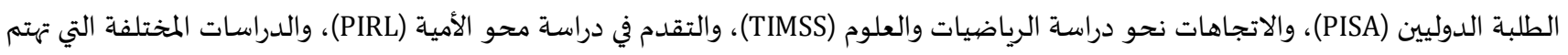

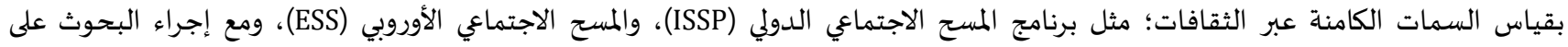
المنظمات، فإن الأسلوب الإحصائي المستخدم هو التحليل العاملي التوكيدي متعدد المجموعة (MGCFA) (McArdle, 1996). 
ومن مساعي وزارة التربية والتعليم الأردنية لمواكبة التطورات في قياس المهارات التعليمية لدى الطلبة وتزويدهم بأعلى المستويات منها، وشعورها بالقلق على طلبة المراحل الأولى التي تمثلها الصفوف الثلاثة الأولى؛ باعتبارها المرحلة الابتدائية التي تحدد مستوى تعليم الطالب في المراحل التعليمية

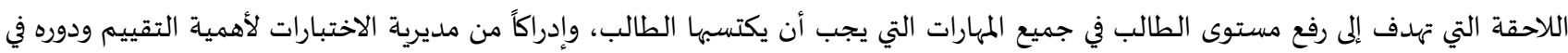

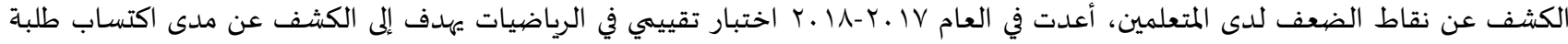

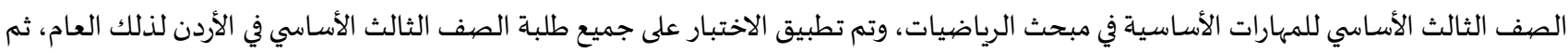

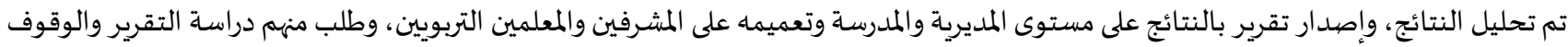

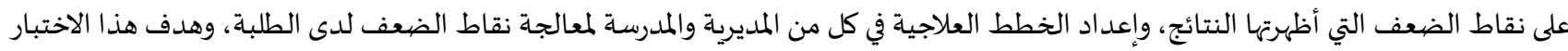

ا. معرفة المستوى التعليمي لطلبة الصف الثالث الأسساسي في المهارات والقدرات الأساسية في مجال الرياضيات. r. تزويد المعلمين بمعلومات عن نقاط القوة والضعف في أداء طلبتهم، ومساعدتهم على متابعة الطلبة ووضيع الخطط العلاجية المناسبة وفقًا لنتائج الاختبارات. r. اتخاذ القرارات المتعلقة بالمناهج على أساس واقعي ومعلومات صحيحة بحيث يركز المنهج على تلك الجوانب والمهارات التي أظهرت نتائج الاختبار ضعف أداء الطلبة عليها. وبسبب أهمية هذا الاختبار والاستخدامات الممكنة لنتائجه في خدمة أصحاب القرار سيتم استخدامها في هذه الحها الدراسة للتأكد من مدى صددقه لما صممم من أجله، ويتألف من (ro) فقرة من نوع الاختيار من متعدد موزعة على محاور التعلم في مادة الرياضيات، وهي: الأعداد والعمليات، الجبر

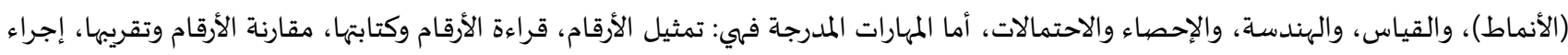

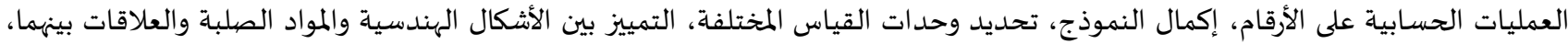

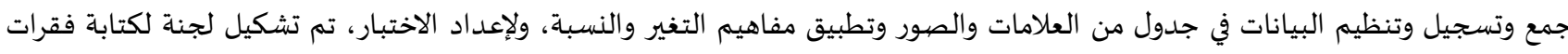

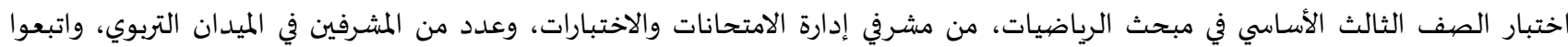

الخطوات التالية:

· بناء الفقرات: تحليل محتوى كتاب الرياضيات للصف الثالثالث الأساسي، ودراسة نتائج التعلم للصف الثالث في المادة المستهدفة في الاختبار،

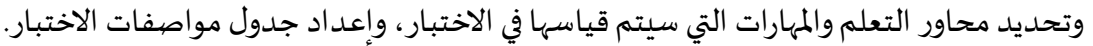

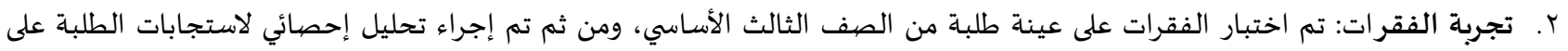
الفقرات لمعرفة قابليتها للقراءة والخصائص السيكومترية مثل: فاعلية البدائل، ومستوى الصعوبة والتمييز للفقرات، ثم تم اختيار الفقرات

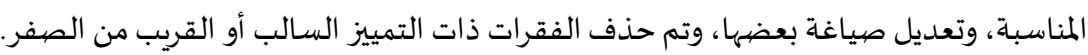

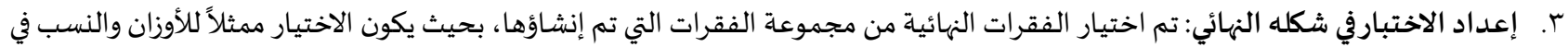
جدول المواصفات الذي تم تطويره ليشمل مؤشرات الأداء.

الدراسات السـابقة:

لقد كانت المقارنات بين المجموعات المختلفة على الاختبارات الوطنية والدولية ودراسة البناء العاملي لهم مدار اهتمام العديد من الدراسات. فقد قام التقي (r (99) بدراسة تهدف للكشف عن مدى تحقق افتراض اللاتغير في مستويات صعوبة الأسئلة من خلال استخدام عينات

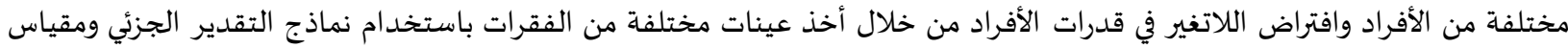

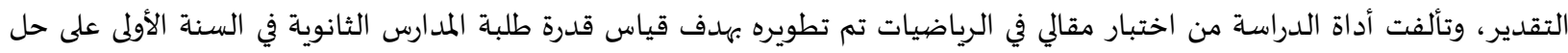

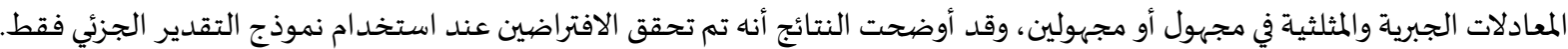
كما هدفت دراسـة آدام وجاري (Adam \& Gary, 2004) لتوضيح تقنيات طريقة التحليل العاملي التوكيدي الأكثر شيوعًا لقياس التكافؤ / اللاتغير في القياس، حيث استخدمت الدراسة مجموعة من البيانات المولدة المختلفة في تشبعات العوامل لاختبار تكافؤ القياس، وأشارت الشارئ النتائج

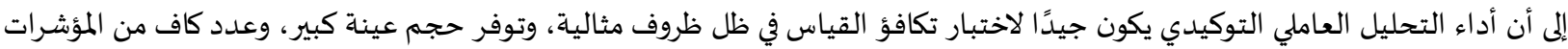

وأجرى محمد (1) ـ إ) دراسـة تهدف إلى قياس اللاتغير العاملي لمقياس فورست للكمالية متعدد الأبعاد الذي يتكون من (10) فقرة باستخدام التحليل العاملي التوكيدي لمجموعات متعددة، ولتحقيق هذا الهدف تم تطبيق المقياس على عينة من (9 (1) طالبًا في كلية التربية - جامعة المنيا،

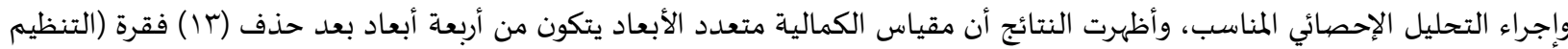


والتوقعات، والنقد الأبوي والمعايير الشخصية، والحساسية للأخطاء، والشكوك تجاه الإجراءات) وأن معاملات الثبات تراوحت بين (ب T, . - Y . .)، وأكدت النتائج مطابقة جيدة للعوامل الأربعة.

كما قدم الزبون (rا •r) دراسة تهدف لاكتشاف اللاتغير في تقدير معلمات فقرات الاختيار من متعدد عند تطبيقها في سياقات مختلفة، ولتحقيق أهد اف الدراسة، تم تطبيق اختبار يتكون من (ب | (1) فقرة من نوع الاختيار من متعدد في الرياضيات، بالإضافة إلى (10) فقرة مشتركة طبقت على عينة من ال|هr طالب وطالبة، وباستخدام البرامج المناسبة في تحليل البيانات كانت هناك فروق ذات دلالة إحصائية لصالح النموذج

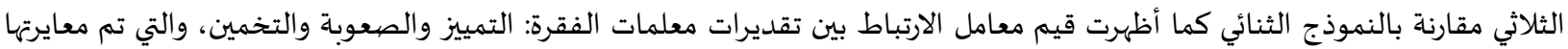
بشكل مستقل وضمن الإطار الكلي للاختبار أهها كانت عالية وذات دلالة إحصائية، وقد وجد أيضًا أن قيم معاملات الارتباط كانت الأعلى عند معايرة الفقرات كعينة منفصلة (بمفردها). يمكن أن نخلص إلى أنه يمكن الحصول على دقة أفضل عند معايرة عينة من الفقرات بشكل مستقل مقارنةً بالمعايرة داخل الإطار الكلي للاختبار.

وكذلك أجرى ديمترف (Dimitrov, 2013) دراسة لفحص بيانات اختبار القدرات اللفظية العامة والبناء العاملي له، والذي يتكون من 70 فقرة من نوع الاختيار من متعدد المطبقة على • إل, 10 طالب وطالبة، ثم تم فحص أحادية البعد للاختبار باستخدام التحليل العاملي التوكيدي،

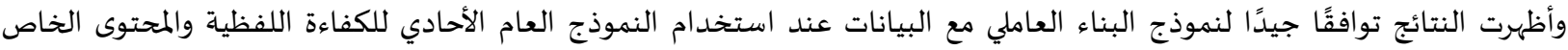
بالنموذج الثلاثي للجوانب المتأصلاة في الكفاءة اللفظية. كما أجرى ايونيس (Ioannis,2014a) دراسة في البناء العاملي للبيانات حسب جنس الطالب (ذكر، أنثى) لاختبار القدرات العامة (GAT) المعد

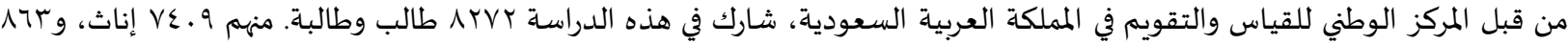

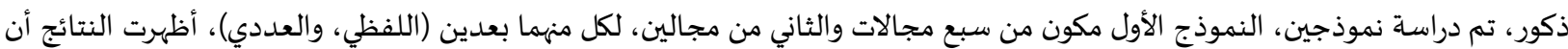
كلا النموذجين يناسب البيانات ويقدم دليل على صحة البناء العاملي لاختبار القدرات العامة (GAT). والهدف الثاني هو دراسة اللاتغير في مئي

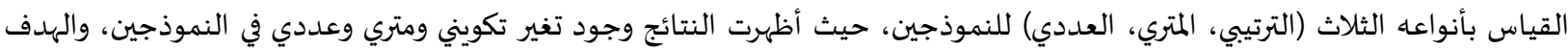
الثالث هو قياس الفروق بين الجنسين عبر المجالات المختلفة باستخدام الفروق في الأوساط الكامنة، حيث أظهرت النتائج أن الأوساط للذكور

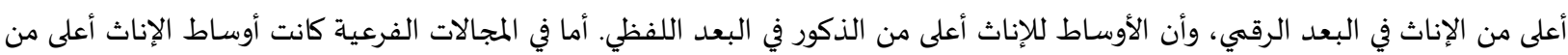

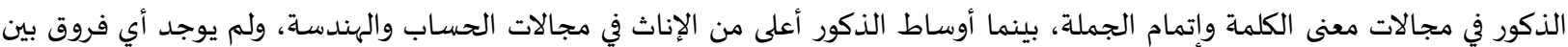
الجنسين في مجالات القراءة والفهم والتحليل الكامن. وأجرى ايونيس (Ioannis, 2014b) دراسة في البناء العاملي للبيانات حسب نوع المدرسة (خاصة، حكومية) لاختبار القدرات العامة (GAT) المعد

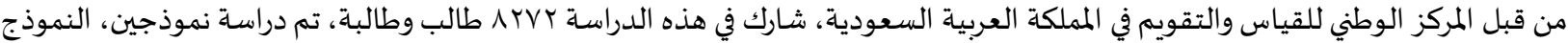

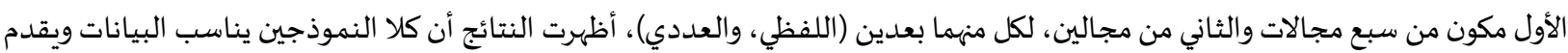
دليل على صحة البناء العاملي لاختبار القدرات العامة (GAT). والهدف الثاني هو دراسة اللاتغير في القياس بأنواعها الثلاث (الترتيبي، المتري،

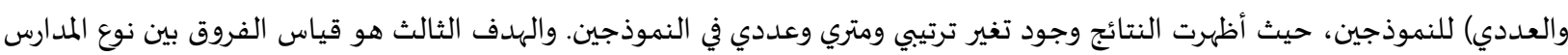
عبر المجالات المختلفة باستخدام الفروق في الأوساط الكامنة، وجد أن أوساط الطلاب في المدارس الخاصة أعلى منها في المدارس العامة في في فئي

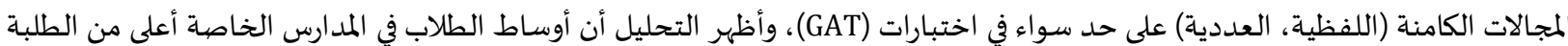

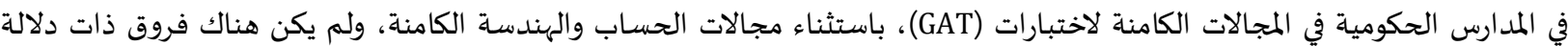
إحصائية بين هذين النوعين من المدارس.

كما درس ايونيس (Ioannis, 2015) البناء العاملي لبيانات اختبار (SAAT) التحصيلي للقبول، الذي يدار من قبل المركز الوطني للقياس

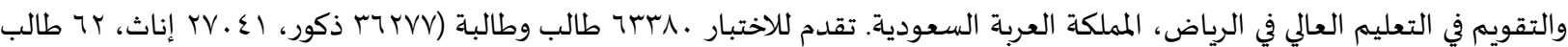
وطالبة لم يحددوا جنسهم). تم دراسة ثلاثة نماذج للبناء العاملي لاختبار (SAAT) كان النموذج الثاني أفضل من النمانه النموذجين الآخرين، وقد بينت النتائج أن جميع النماذج تناسب البيانات وتقدم دليلاً على صحة البناء العاملي لمعيار اختبار (SAAT) التحصيلي للقبول. وأظهرت النتائج وجود

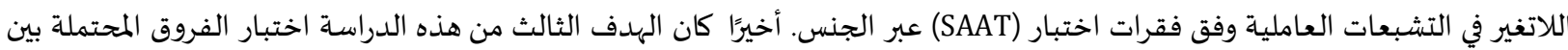
الجنسين في البناء العاملي لاختبار (SAAT). باستخدام أوساط الفروق الكامنة، حيث أظهرت النتائج أن الأوساط للإناث أعلى منها للذكور في علم إهن

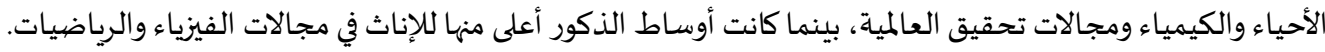
كما قارن دافيدوف وزملاؤه (Davidov et al., 2015) قياسات الاتجاهات نحو الهجرة في المسح الاجتماعي الأوروبي: باستخدام اللاتغير الدقيق الكلاسيكي بمقابل لاتغير القياس التقريبي، حيث تم تحليل بيانات المسح الدولي بتواتر متزايد لاستقصاء ومقارنة الاتجاهات نحو الهجرة وفحص بهص

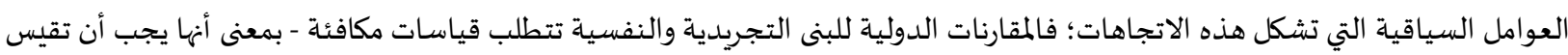


نفس المفهوم على نفس أداة القياس، تؤدي أغلب الطرق التقليدية لتقييم لاتغير القياس لاستنتاج أن القياسات لا يمكن مقارنتها عبر الدول، تم

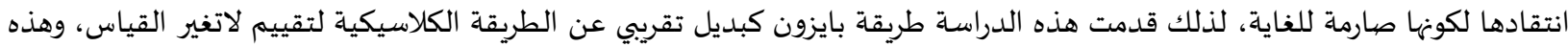
الطريقة تسمح بتغيرات صغيرة في معلمات القياس عبر المجموعات، وتم التحدث عن التحليل العاملي التوكيدي متعدد المجموعة كنقطة انطلاق، حيث تم اختبارات اللاتغير التقريبي والكلاسيكي على مقياس الاتجاهات نحو الهجرة الذي نفذ في المسح الاجتماعي الأوروبي (ESS)، وتم

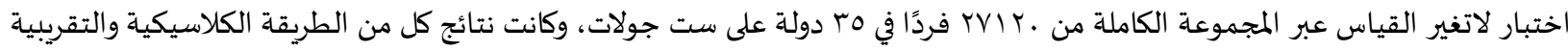
مختلفة تمامًا، فالطريقة التقريبية أثبتت تحقق خاصياة لاتغير القياس في كل جولات المقياس البيئي والاجتماعي (ESS)، وبالتالي السماح للباحثين

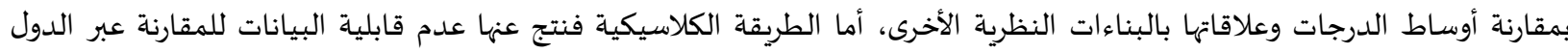
والفترات الزمنية المتعددة بسبب عددها الكبير.

وفي ضوء ما تقدم عرضها من الدراسات السابقة يمكن ملاحظة: أنها جميعًا هدفت للكشف عن لاتغير القياس باستخدام التحليل العاملي

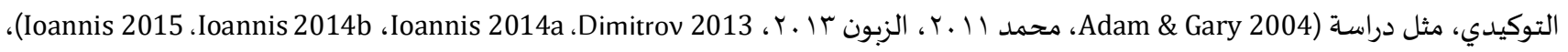
كما أنه لم يتم دراسة الاختبار التقييمي لمهارات الرياضيات للصف الثالثالث الأساسي نهائيًا، لذلك جاءت هذه الدراسة لتأخذ نوعًا من الخصهوصية في

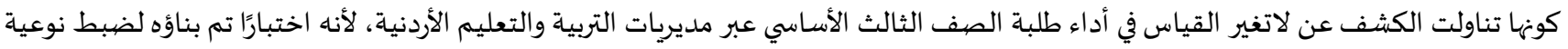

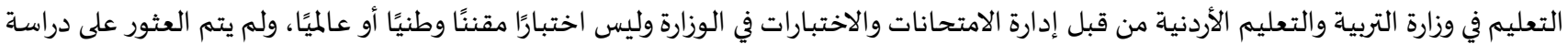

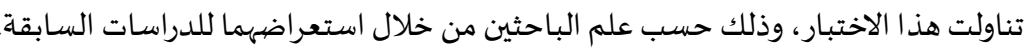

مشكلة الدراسـة:

أدت التغييرات المستمرة في مجال القياس والتقييم إلى ظهور منهجيات إحصائية حديثة للمقارنة بين المدارس أو المناطق المختلفة باستخدام أدوات القياس على شكل اختبارات معرفية أو مقاييس شخصية، لذلك كان علينا التفكير فيما إذا كان من المنطقي افتراض أن هذه النهات الأدوات ليست

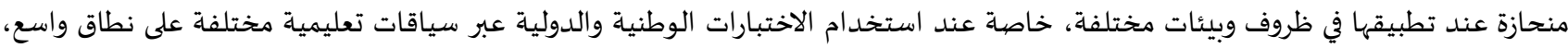
وخصوصًا في البلدان التي تطبق اختبارات على مستوى واسع، مثل اختبار TEMIS PISA ، واختبار تقييم طلبة الصف الثالث الأساسي لمهارات الرياضيات،

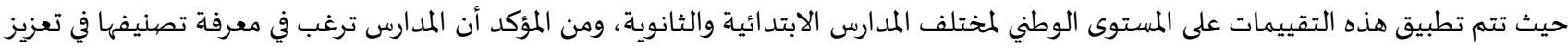
هذه المهارات، ولتحقيق ذلك، يجب مواجهة التحديات المنهجية الفريدة والتغلب عليها. يمكن استخدام التحليل العاملي التوكيدي متعدد المجموعة لمقارنة المجموعات علتهات على أوساط عاملهاتها (على سبيل المثال، مستوى مهارة واحد)؛

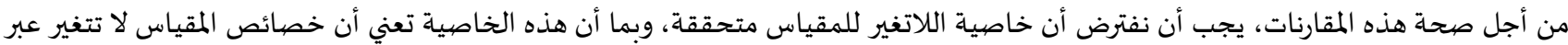

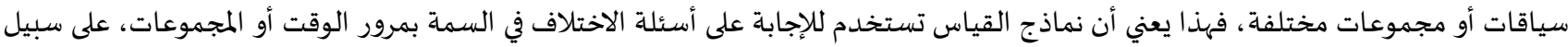

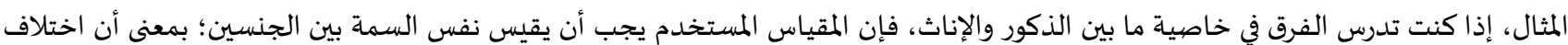

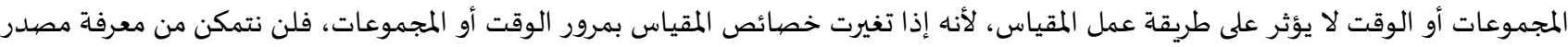

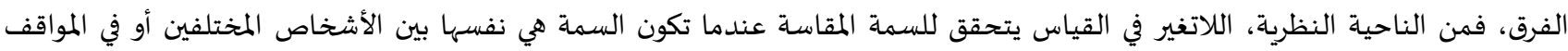
المختلفة، على سبيل المثال، عند تطبيق هذا المفهوم على سمات غير معرفية، مثل تحفيز الطلبة، فنحن نفترض أن الفقرات في مقياس التحفيز يتم

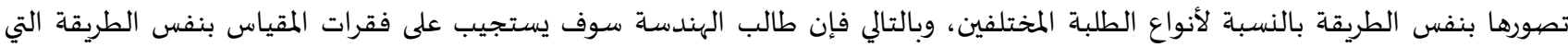
يستجيب فها طالب الفنون، ولأهمية تحقق خاصية اللاتغير ظهرت عدة طرق إحصائية لاختبارها، والتي تشارك جميعها في إجراء تحقيق في العديد من

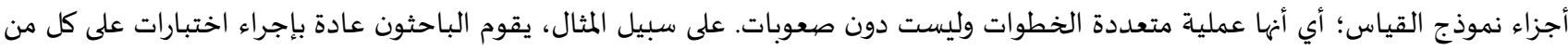

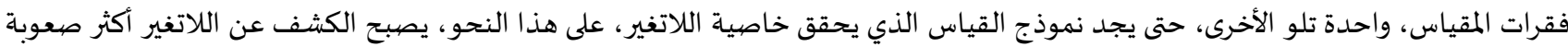

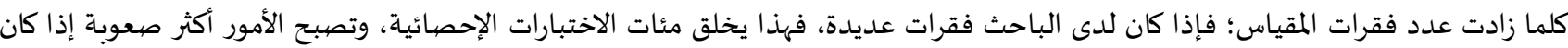

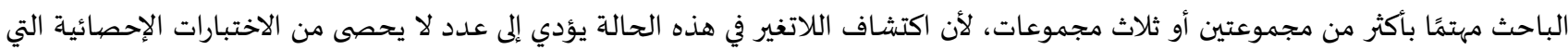

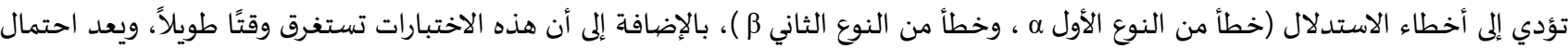

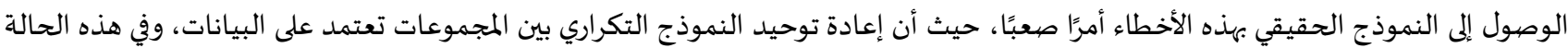

يعتمد على الصدفة؛ أي أنه لا يمكن تعميم هذه النتائج على عينات أخرى (MacCallum, Roznowski, \& Necowitz, 1992). فالهدف العام من الدراسة هو الكشف عن اللاتغير في القياس عند استخدام مقاييس واختبارات وطنية تتكون من فقرات ثنائية الاستجابة إنابة بخطوات واضحة يمكن لأي باحث اتباعها والتحقق من خاصية اللاتغير لأي اختبار كان، ولتحقيق ذلك، فإن التحليل العاملي متعدد المجموعة

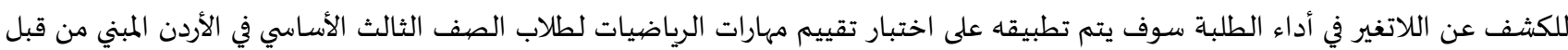
إدارة الامتحانات والاختبارات الأردنية، وستسعى هذه الدراسة للإجابة عن الأسئلة التالية: 
السؤال الأول: هل نموذج العوامل السبعة المقترح لمحتوى اختبار الرياضيات (تمثيل الأعداد، مقارنة الأعداد، العمليات الحسابية على الأعداد، الجبر

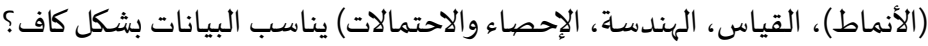

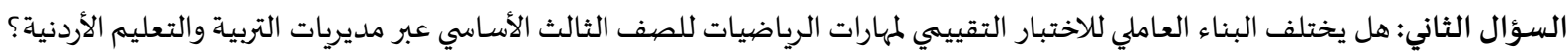

أهمية الدراسة:

تنبع أهمية الدراسة من أهمية خاصية اللاتغير في القياس وتركيزها على الجانب العملي، حيث لاحظ الباحثان في حدود معرفتهم قلة وجود دراسـات تناولت لاتغير القياس في فقرات الاختبارات، أو المقاييس النفسية، والدراسات الاستقصيائية الدولية، وانعدام الدراسات التي تناولت اللاتغير في القياس لفقرات الاختبار التقييمي لمهارات الرياضيات، لذلك، توفر هذه الدراسة إطارًا نظريًا يتضمن مجموعة التهات من الحقائق النظرية والإحصائية

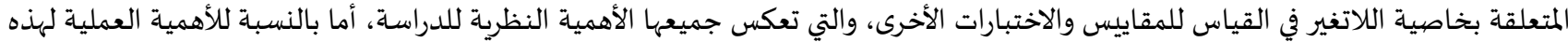
الدراسة، فهي تنبع من محاولة لتوفير المزيد من مؤشرات الصدق للاختبار التقييمي لمهارات الرياضيات في مجتمع طلبة الصف الثالث الأساسي في الأردن.

التعريفات الاصطلاحية والإجر ائية: اللاتغير في القياس Measurement Invariance: هو الحالة التي لا تؤثر فيها الاختلافات الثقافية في قياس السمات الأسـاسية؛ أي أن هذه الخصائص المتأصلة متشـابهة مع المجموعات المختلفة لأن الاختلافات الفريدة للفقرات مستقلة عن الثقافات المختلفة.

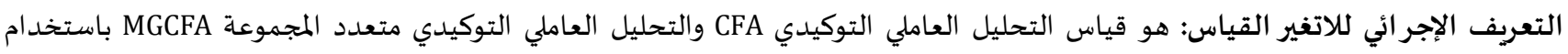
مؤشرات المطابقة الجيدة (CFI, RMSEA, SRMR, لفقرات الاختبار التقييمي لمهارات الرياضيات للصف الثالث من التعليم الأساسي بحيث يكون

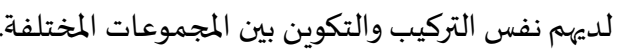
الاختبار التقييمي للصف الثالث الأساسي لمبحث الرياضيات: اختبار من إعد اد وزارة التربية والتعليم ممثلة بمديرية الامتحانات في عام \ل ـ ب لقياس

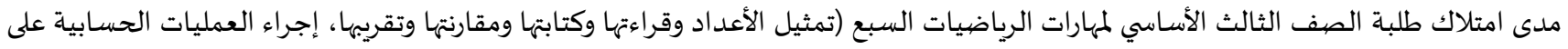
الأعداد، وإكمال النمط، وتحديد وحدات القياس المختلفة، والتمييز بين الأشكال الهندسية والمجسمات والعلاقات بينهما، وجمع البيانات، وتسجيلها

وتنظيمها في جدول الإشارات والصور، وتطبيق مفاهيم التغير والنسبة). التعريف الإجر ائي للاختبار التقييهي للصف الإساتوالهيالث الأساسي لمبحث الرياضيات: هو اختبار وطني تعده وزارة التربية والتعليم الأردنية يهدف لقياس

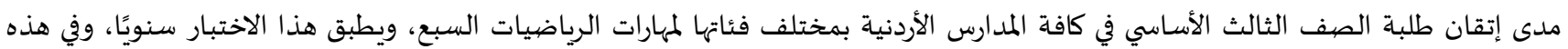

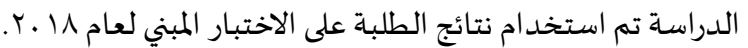

$$
\text { محددات الدراسـة: }
$$

اقتصرت هذه الدراسة على طلبة الصف الثالث الأساسي في المدارس الأردنية للعام الدراسي IN/T. V . م، كما اقتصرت على مهارات مبحث

$$
\text { الرياضيات للصف الثالث الأسـاسي. }
$$

\section{منهج الدراسة:}

المنهج المناسب للكشف عن اللاتغير في قياس اختبار مهارات الرياضيات لطلبة الصف الثالث الأسـاسي من خلال مديريات التربية والتعليم لعام

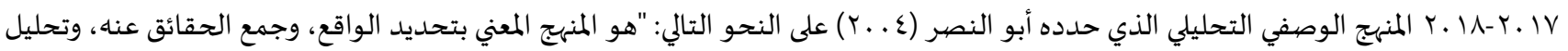
بعض جوانبه، بطريقة تسهم في تطويره" (ص ابرا)، حيث استخدم الباحثان طريقة التحليل العاملي متعدد المجموعة ثم قدما وصفًا للتحليلات

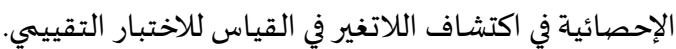

مجتمع الدراسـة وعينتها:

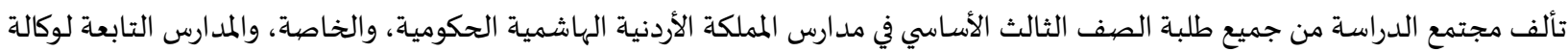

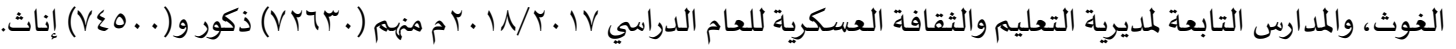
ويبين الجدول الآتي أعداد الطلبة المتقدمين للاختبار ونسبهم على مستوى المملكة.

\begin{tabular}{|c|c|c|}
\hline نسبة المتقدمين للاختبار & أعداد الطلبة الذين تقدموا فعليًا للاختبار & أعداد الطلبة المرشحين للاختبار كما \\
\hline$\%$ \%. & $1 \leqslant V I T$. & $17 r . \varepsilon 7$ \\
\hline
\end{tabular}

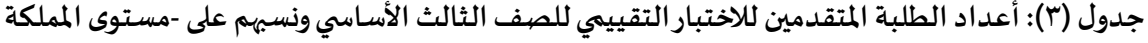


قسّم مجتمع الدراسة إلى عينتين متساويتين وبشكل عشوائي، حيث تقدمت العينة الأولى إلى اختبار اللغة العربية فيما تقدمت العينة الثانية

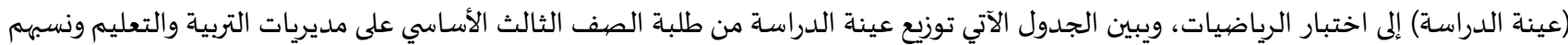

على مستوى المملكة.

جدول (ع): توزيع عينة الدراسة من طلبة الصف الثالث الأساسي على مديريات التربية والتعليم

\begin{tabular}{|c|c|c|c|c|c|}
\hline نسبة المديرية إلى مجتمع & عدد الطلبة & اسم المديرية & نسبة المديرية إلى مجتمع & عدد الطلبة & اسم المديرية \\
\hline$\%$ & 9人र & البادية الشمالية الشرقية & $\%$ & qITV & التعليم الخاص \\
\hline$\%$ & 909 & البادية الشمالية الغربية & $\%$ & rMAq & قصببة عمان \\
\hline$\%$ & 0177 & الزرقاء الأولى & $\%$ & $1 \leqslant Y \varepsilon$ & الجامعة \\
\hline$\%$ & TrY. & الزرقاء الثانية & $\%$ & rq\&. & القويسمة \\
\hline$\%$ & $r \varepsilon \cdot r$ & الرصيفة & $\%$ & $r 990$ & ماركا \\
\hline$\%$ & $19 r$. & قصبة السلط & $\%$ & 1110 & وادي السير \\
\hline$\%$ & $v .7$ & دير علا & $\%$ & $v \cdot \Lambda$ & ناعور \\
\hline$\%$ & orr & الشونة الجنوبية & $\%$ & $7 \leqslant 7$ & سحاب \\
\hline$\%$ & TITO & عين الباشا & $\%$ & 00 & الجيزة \\
\hline$\%$ & 1180 & قصبة الكرك & $\%$ & OAr & الموقر \\
\hline$\%$ & QTr & المزار الجنوبي & $\%$ & $10 \leqslant 7$ & 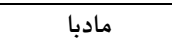 \\
\hline$\%$ & $\varepsilon 9$. & القصر & $\%$ & rrI & ذيبان \\
\hline$\%$ & $79 \varepsilon$ & الأغوار الجنوبية & $\%$ & rar. & قصبة إربد \\
\hline$\%$ & VTr & الطفيلة & $\%$ & (זry & بني عبيد \\
\hline$\%$ & $r .$. & بصيرا & $\%$ & $7 \leqslant 9$ & المزار الشمالي \\
\hline$\%$ & rov & معان & $\%$ & $0 \leqslant 7$ & الطيبة والوسطية \\
\hline$\%$ & rrq & البتراء & $\%$ & $1 . \lambda r$ & الكورة \\
\hline$\%$ & $\mid \leqslant 1$ & الشوبك & $\%$ & $1.1 \varepsilon$ & 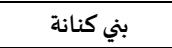 \\
\hline$\%$ & $7 \pi$ & البادية الجنوبية & $\%$ & 1109 & الرمثا \\
\hline$\%$ & 1709 & العقبة & $\%$ & V10 & الأغوار الشمالية \\
\hline$\%$ & $0 v .9$ & وكالة الغوث & $\%$ & r.VI & جرش \\
\hline$\%$ & $\sum r$ & الثقافة العسكرية & $\%$ & IV.V & عجلون \\
\hline & & & $\%$ & $r .00$ & قصبة المفرق \\
\hline$\%$ & \multicolumn{2}{|c|}{ نسبة الممديريات إلى مجتمع الدراسة } & $V T \varepsilon \varepsilon \wedge$ & \multicolumn{2}{|c|}{ المجموع } \\
\hline
\end{tabular}

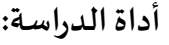

تكونت أداة الدراسـة من: • اختبار مكون من (ro) فقرة من نوع الاختيار من متعدد موزّعة على محاور التعلم في مبحث الرياضيات وهي: الأعداد والعمليات، والجبر

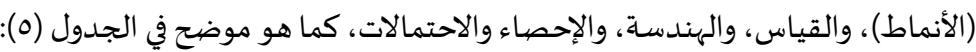

جدول (0): توزيع فقرات الاختبارعلى نتاجات التعلم ومحاوره

\begin{tabular}{|c|c|c|c|}
\hline أرقام الفقرات & 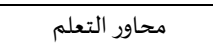 & وصف النتاج & رقم النتاج \\
\hline 1 & \multirow[t]{10}{*}{ 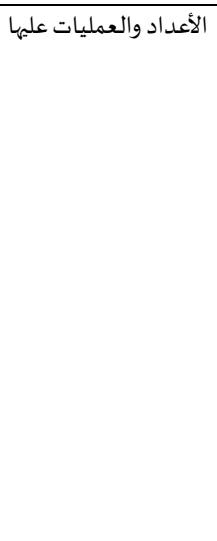 } & يقرأ الأعداد (باستخدام الرموز بالكلمات) حتى (9999) & 1 \\
\hline r. r & & يستخدم الطريقة التحليلية لتمثيل الأعداد ضمن (9999) & r \\
\hline$\varepsilon$ & & يمثل الأعداد حتى ( . . ) على خط الأعداد أو جزء منه & r \\
\hline $1 \varepsilon, 1 T$ & & 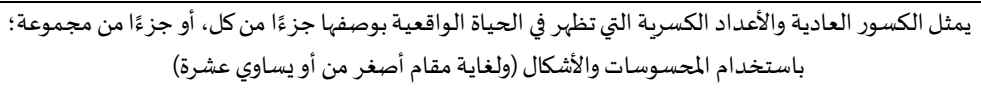 & $\varepsilon$ \\
\hline$\circ$ & & يقارن الأعداد ضمن (ع) منازل، ويرتبها & $\circ$ \\
\hline 1. & & يضرب عددًا من منزلة واحدة بعدد من مضاعفات العشرة أو مئة ذهنيًا & 1 \\
\hline 11 & & يجمع الأعداد ضمن (ع) منازل بطلاقة، ويطرحها باستخدام استراتيجيات متنوعة، وبحكم على الحل & $\mathrm{v}$ \\
\hline 9 & & يجمع الكسور ذات المقامات الموحدة ويطرحها، ويحدد كسرين مجموعهما واحد صحيح & $\wedge$ \\
\hline 1 & & يذكر حقائق القسمة ضمن حقائق الضرب & 9 \\
\hline IT،八،V & & يحل مسائل حياتية باستخدام العمليات الأربع على الأعداد، وعمليتي الجمع والطرح على الكسور (خطوتان على & 1. \\
\hline
\end{tabular}




\begin{tabular}{|c|c|c|c|}
\hline 17.10 & \multirow[t]{2}{*}{ 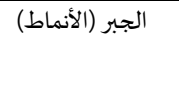 } & يكمل أنماطاً عددية تتضمن جمع أو طرح مقدار ثابت & 11 \\
\hline IN.IV & & يوضح قاعدة النمط، ويقدم تنبؤات & it \\
\hline rt & \multirow[t]{2}{*}{ الهندسة } & يصف مجسمات ثلاثية الأبعاد ويسميها مثل: (المكعب، الكرة، المخروط، الأسطوانة)، ويستخدم مسميات الأشكال & ir \\
\hline rr & & يصف العلاقات بين الأشكال الثنائية الأبعاد والثلاثية الأبعاد، مثل: الكرة، والدائرة، والمربع، والمكعب & $1 \varepsilon$ \\
\hline 41.19 & \multirow[t]{2}{*}{ القياس } & يحدد وحدات القياس المتعلقة بالطول ويستخدمها مثل: (ميليمتر، وكيلومتر)، الوقت (يوم، وأسبوع، وشهر، وسنة)، والسئل & 10 \\
\hline r. & & يقرأ الساعة بالدقائق & 17 \\
\hline TO, TE & الإحصاء والاحتمالات & يحل مسائل باستخدام البيانات الممثلة & IV \\
\hline
\end{tabular}

أما المهارات التي شملها اختبار الرياضيات فهي ناتجة عن تحليل محتوى كتاب الرياضيات للصف الثالث الأساسي من قبل اللجنة المشكلة من

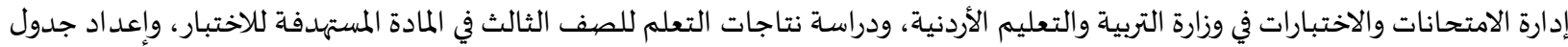

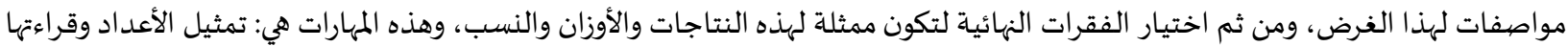
وكتابتها، مقارنة الأعداد وتقريها، وإجراء العمليات الحسابية على الأعداد، وإكمال النمط، وتحديد وحدات القياس المختلفة، وتمييز الأشكال الهندسية والمجسمات والعلاقات بينها، وجمع البيانات وتسجيلها وتنظيمها بجدول الإنشارات واتهات والصهور وتطبيق مفهومي التغير والنسبة. والجدول (7) التالي يبين توزيع فقرات الاختبار على مهارات مبحث الرياضيات السبع الممثلة للنتاجات والأوزان والنسب في جدول فيهات مواصفيات

الاختبار التقييمي المبني لهذا الغرض:

جدول (7): توزيع فقرات الاختبار على مهارات مبحث الرياضيات السبع التي يقيسها الاختبار التقييهي

\begin{tabular}{|c|c|c|}
\hline 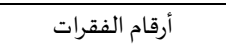 & اسم المهارة & رقم المهارة \\
\hline $\mid \varepsilon, I r \cdot r \cdot r \cdot 1$ & تمثيل الأعداد وقراءتها وكتابها، وتمثيل الكسور العادية والأعداد الكسرية باستخدام المحسوسات والأشكال & 1 \\
\hline $0 ، \varepsilon$ & مقارنة الأعداد وتقربيها & r \\
\hline 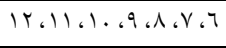 & إجراء العمليات الحسابية على الأعداد، وعمليتي الجمع والطرح على الكسور ( خطوتان على الأكثر ) & r \\
\hline 11.18 .17 .10 & إكمال النمط وتوضيح قاعدة النمط & $\varepsilon$ \\
\hline YI. T. .19 & تحديد وحدات القياس المختلفة المدية & 0 \\
\hline rT, r & تمييز الأشكال الهندسية والمجسمات والعلاقات بينها & 7 \\
\hline TO,TE & جمع البيانات وتسجيلها وتنظيمها بجدول الإشارات والصور & v \\
\hline
\end{tabular}

نتائج الدراسـة ومناقشتها:

للإجابة عن أسئلة الدراسة تم استخدام برنامج (Mplus v8.4)؛ وذلك للحصيول على قيم مؤشرات ملاءمة النموذج المقترح من قبل إدارة

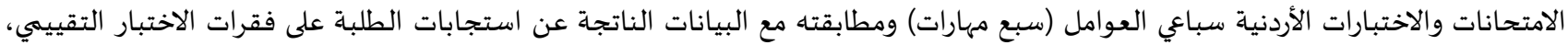
وكانت النتائج على النحو الآتي: فيما يتعلق بالإجابة عن السؤال الأول: هل نموذج العوامل السبعة المقترح لمحتوى اختبار الرياضيات (تمثيل الأعداد، مقارنة الأعداد، العمليات

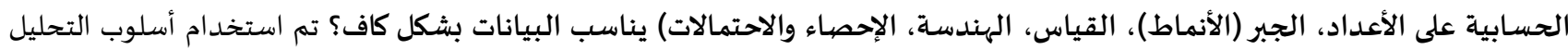

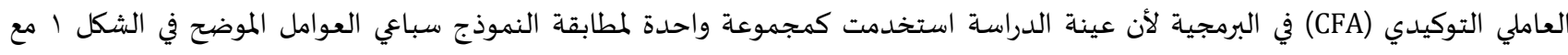

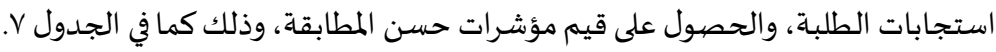




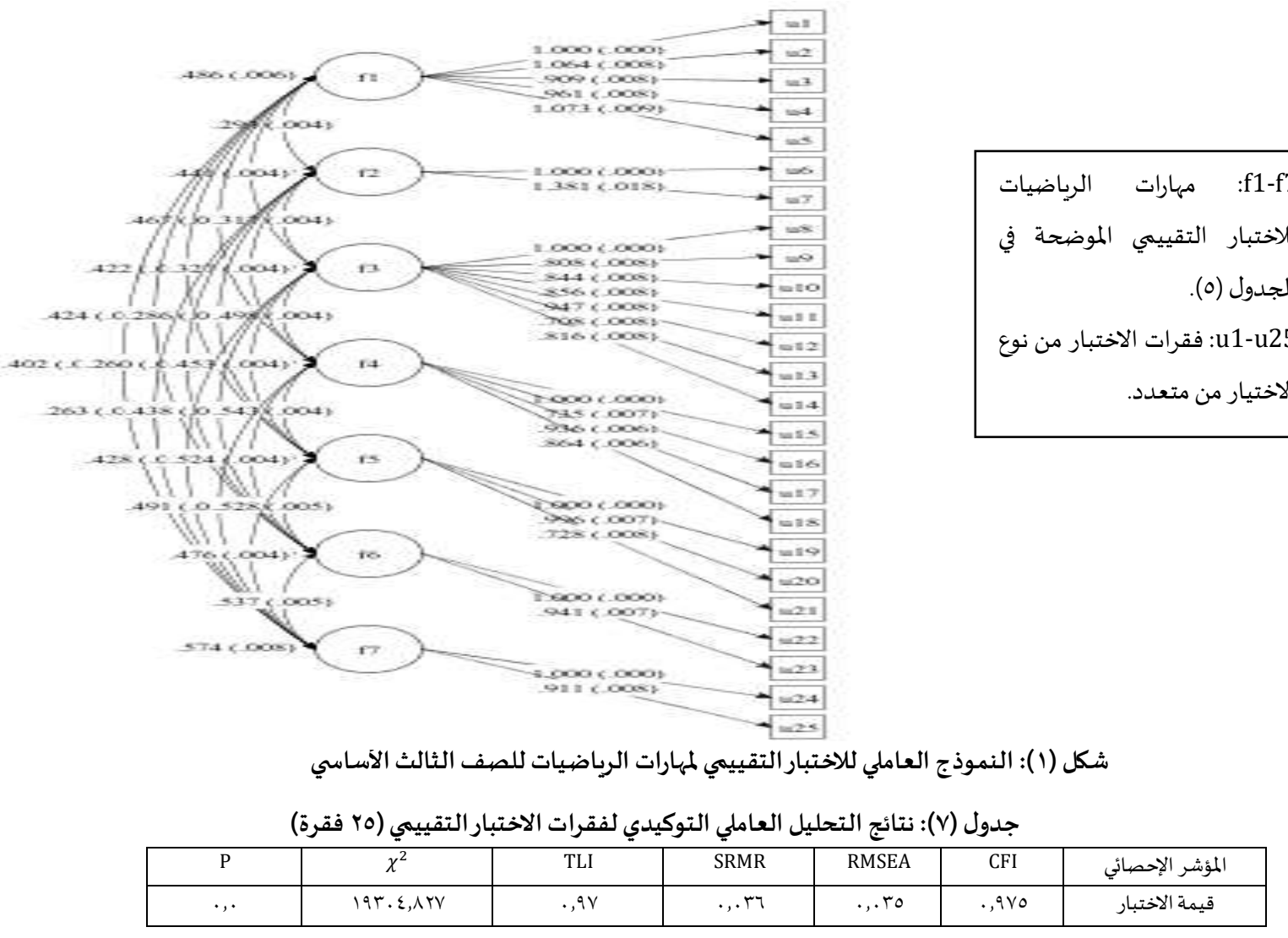

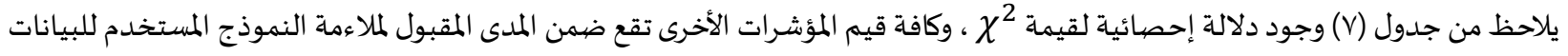

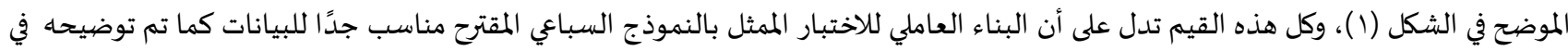

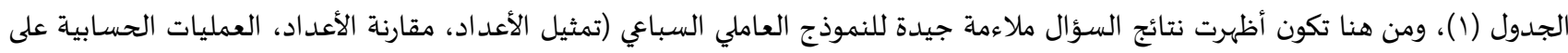

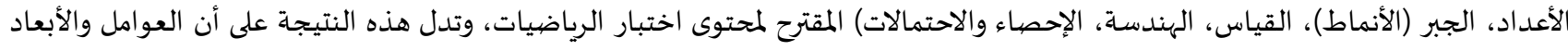

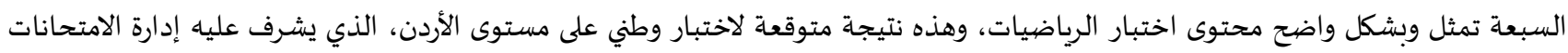

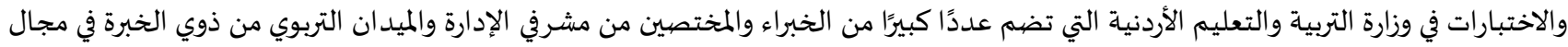

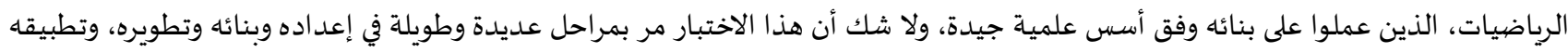

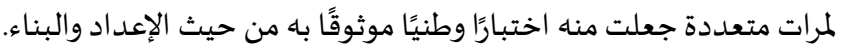

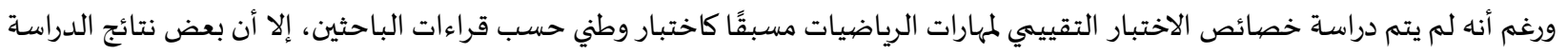

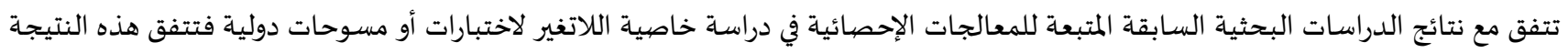

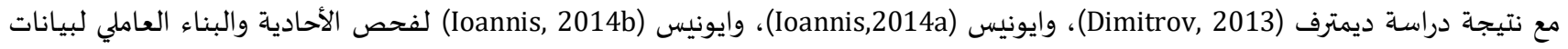

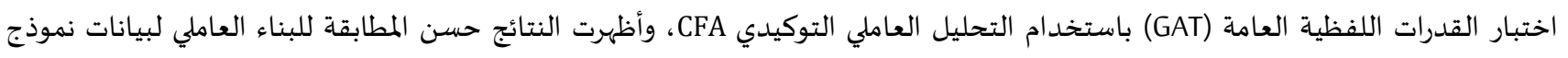

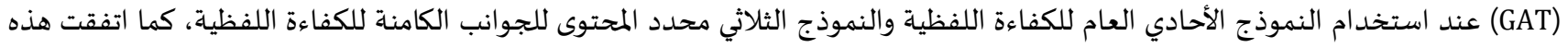

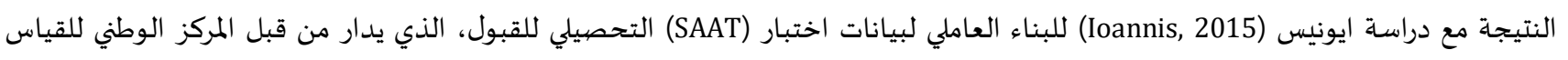

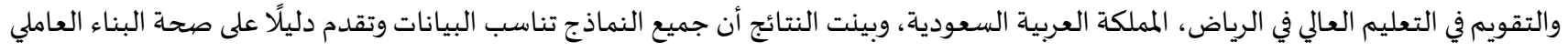
لمعيار اختبار (SAAT) التحصيلي للقبول.

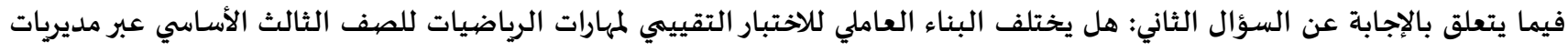

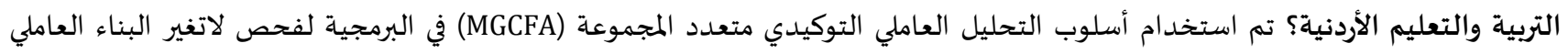

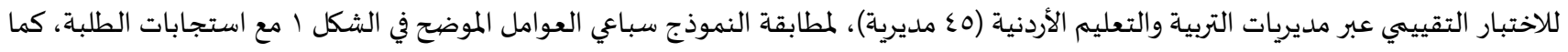

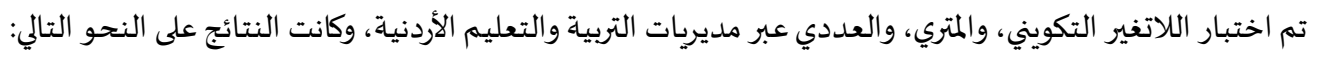


أولًا: اللاتغير التكويني باختلاف مديرية التربية والتعليم الأردنية (0ع مديرية):

تم استخدام التحليل العاملي التوكيدي متعدد المجموعة (MGCFA) في برمجية (Mplus v8.4) على البيانات كاملة لاختبار اللاتغير التكويني حسب النموذج المقترح الموضح في الشكل r ، الذي يتم إجراؤه بدون أية قيود (No constraints)، وفي أول مرحلة من مراحل التحليل باستخدام البرمجية تم استبعاد (9) مديريات تباعًا، وذلك كما أوردنا سـابقًا في الإطار النظري بما أن الاختبار التقييمي ذي فقرات ثنائية الاستجابة فيتم حصر مدرات

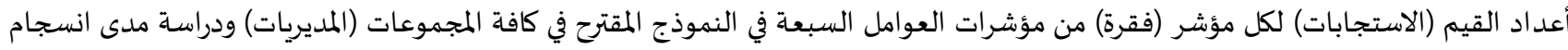

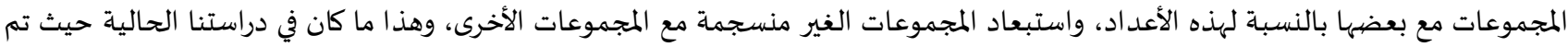
استبعاد مجموعاة من المديريات هي: (التعليم الخاص، والجامعاة، والقويسمة، وسحاب، ومادبا، وقصبة إربد، والرمثا، والأغوار الشمالية، وعجلون).

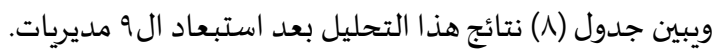

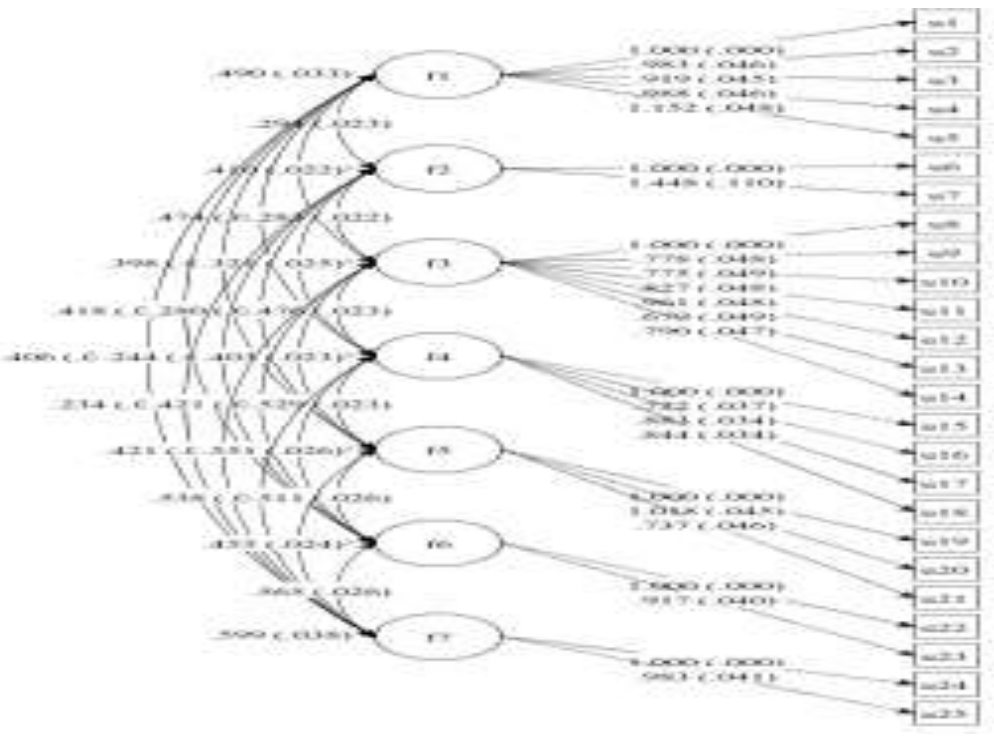

شكل (Y): نموذج اللاتغير التكويني (أ) للاختبار التقييمي وفق متغير مديريات التربية والتعليم البr

جدول (^): نتائج اختبار اللاتغير التكويني (أ) وفقًا لمديريات التربية (جس مديرية)

\begin{tabular}{|c|c|c|c|c|c|c|c|c|}
\hline $\mathrm{P}$ & $\chi^{2} / d f$ & $d f$ & $\chi^{2}$ & TLI & SRMR & RMSEA & CFI & المؤشر الإحصائي \\
\hline.,. & $r, .90$ & $91 \leq \varepsilon$ & 19100,500 & . 974 &., $.0 \varepsilon$ & 更, &., $9 V r$ & قيمة الاختبار \\
\hline
\end{tabular}

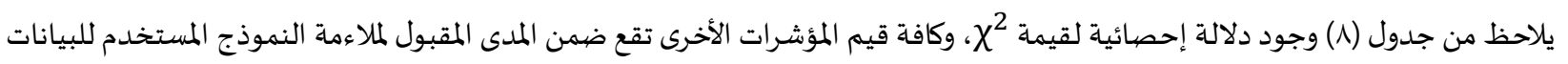
الموضح في الشكل (r)، وهذا يدل على أن البناء العاملي سباعي العوامل للاختبار مناسب للبيانات بشكل كافٍ عبر مديريات التربية والتعليم الأردنية

ال(r).

ثانيًا: اللاتغير المتري باختلاف مديرية التربية والتعليم الأردنية (جس مديرية):

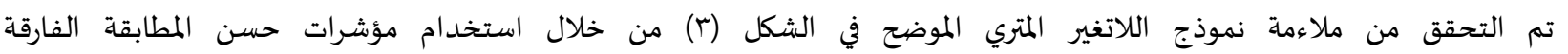

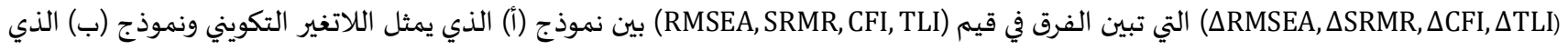

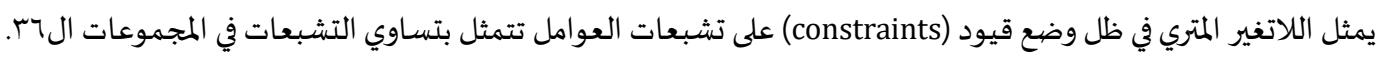




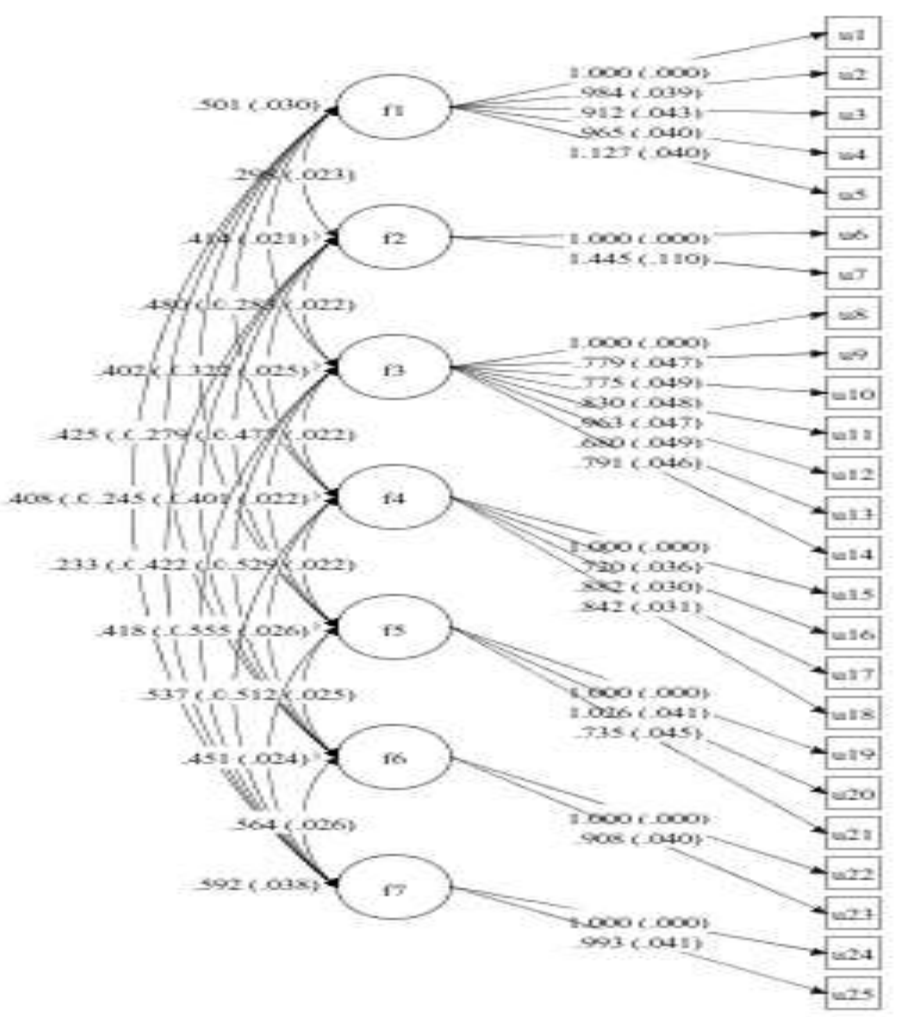

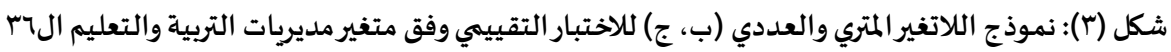

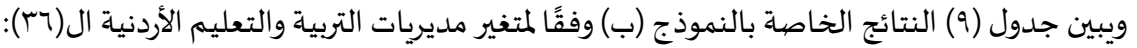

جدول (9): نتائج نموذج اللاتغير المتري (ب) وفقًا لمديريات التربية (جس مديرية)

\begin{tabular}{|c|c|c|c|c|c|c|c|c|}
\hline $\mathrm{P}$ & $\chi^{2} / d f$ & $d f$ & $\chi^{2}$ & TLI & SRMR & RMSEA & CFI & المؤشر الإحصائي \\
\hline .,. & $r, .97$ & $90 r 9$ & $199 \vee \varepsilon, \lambda \vee$. & . &., $0 \leqslant$ & תr & . & قيمة الاختبار \\
\hline
\end{tabular}

يُلاحظ من جدول (9) أن النموذج المتري يناسب البيانات لوجود دلالة إحصائية لقيمة 2ح، وكافة قيم المؤشرات الأخرى تقع ضمن المدى المقبول

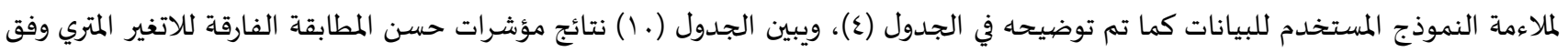

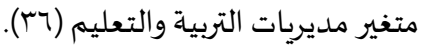

جدول ( ـ (): نتائج مؤشرات حسن المطابقة الفارقة للاتغير المتري وفقًا لمديريات التربية (جس مديرية)

\begin{tabular}{|c|c|c|c|c|c|c|}
\hline$\Delta d f$ & $\Delta \chi^{2}$ & TLI $\Delta$ & SRMR $\Delta$ & RMSEA $\Delta$ & CFI $\Delta$ & المؤشر الإحصائي \\
\hline r 10 & 119,010 &.,$\ldots$ &.,$\ldots$ &.,$\ldots$ &.,$\ldots 1$ & قيمة الاختبار \\
\hline
\end{tabular}

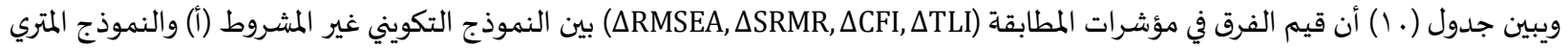

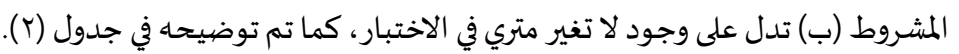

ثالثًا: اللاتغير العددي باختلاف مديرية التربية والتعليم الأردنية (جس مديرية): تم اختبار اللاتغير العددي من خلال استخدام المؤشرات الفارقة (هRMSEA, بين نموذج (ب) الذي يمثل اللاتغير المتري ونموذج (ج) الذي يمثل اللاتغير العددي في ظل وضع قيود (RMSEA, SRMR, CFI, TLI) تقاطعات العوامل (intercepts) تتمثل بتساوي التقاطعات في المجموعات ال بس، ويبين جدول (11) النتائج الخاصة بالنموذج (ج) وفقًا لمتغير مديريات

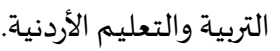

جدول (11): نتائج اختبار اللاتغير العددي (ج) وفقًا لمديريات التربية (جس مديرية)

\begin{tabular}{|c|c|c|c|c|c|c|c|c|}
\hline$P$ & $\chi^{2} / d f$ & $d f$ & $\chi^{2}$ & TLI & SRMR & RMSEA & CFI & المؤشر الإحصائي \\
\hline.,. & $r, .97$ & $90 \% 9$ & $199 \vee \varepsilon, \wedge \vee$. & . 974 &., $0 \leqslant$ & ת & . & قيمة الاختبار \\
\hline
\end{tabular}


يُلاحظ من جدول (1) أن النموذج العددي يناسب البيانات لوجود دلالة إحصائية لقيمة 27، وكافة قيم المؤشرات الأخرى تقع ضمن المدى

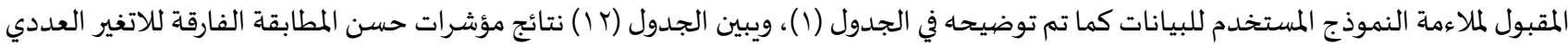

وفق متغير مديريات التربية والتعليم (بr).

جدول (r ا): نتائج مؤشرات حسن المطابقة الفارقة للاتغير العددي وفقًا لمديريات التربية (جس مديرية)

\begin{tabular}{|c|c|c|c|c|c|c|}
\hline$\Delta d f$ & $\Delta \chi^{2}$ & TLI $\Delta$ & SRMR $\Delta$ & RMSEA $\Delta$ & CFI $\Delta$ & $\ldots$ \\
\hline$\cdot$ & $\ldots$ &,$\ldots$ & $\ldots$ & $\ldots$ & $\ldots$ & $\ldots$ \\
\hline
\end{tabular}

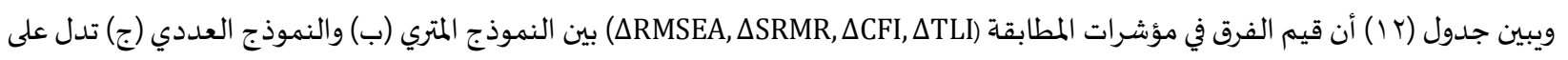
وجود لا تغير عددي في الاختبار، كما تم توضيحها في جدول (r)، ونلاحظ انطباق النموذج المتري والعددي وهذا يؤكد أن الاختبار حقق خاصية اللاتغير في القياس عبر المديريات الجبr. أظهرت نتائج السؤال الثاني وجود لاتغير كلي في القياس للبناء العاملي السباعي المقترح للاختبار التقييمي لمهارات الرياضيات باختلاف مديرية

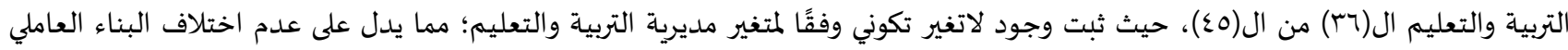
السباعي المقترح لاختبار الرياضيات، ويمكن عزو ذلك إلى صدق الاختبار والتزام الهيئات المشرفة على إعداده بالمعايير المتفق عليها في المحتوى

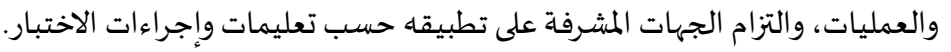

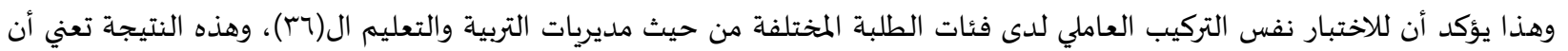
الفروق بين الأوساط الحسابية للأداء على الاختبار من قبل الطلبة في هذه المديريات تعزى لاختلاف خصائص تلك الفئات وقدراتها، وليس للاختلاف في

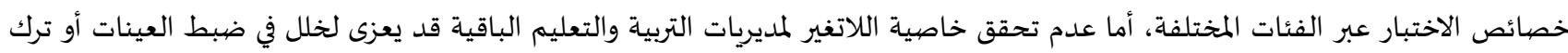

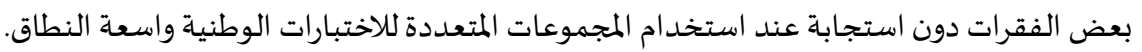

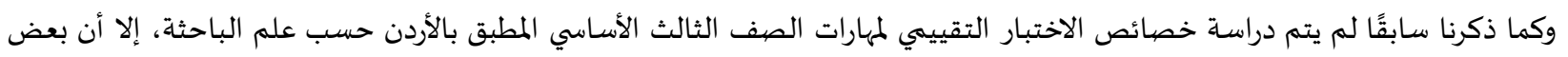

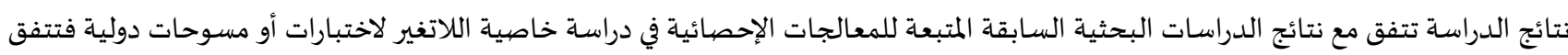
هذه النتيجة مع نتيجة دراسة ديمترف (Dimitrov, 2013)، وايونيس (Ioannis,2014a)، وايونيس (Ioannis, 2014b) لدراسة اللاتغير في القياس بأنواعه الثلاث (التكويني، المتري، العددي) باستخدام التحليل العاملي التوكيدي متعدد المجموعة دGCFA، وأظهرت النتائج وجود تغير تكويني ومتري

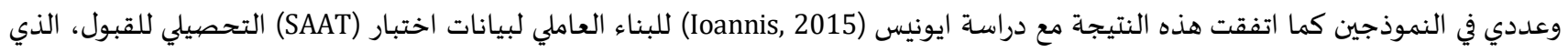

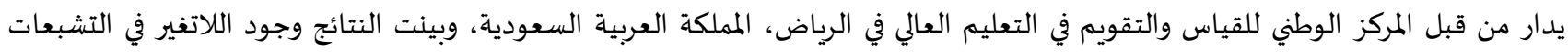

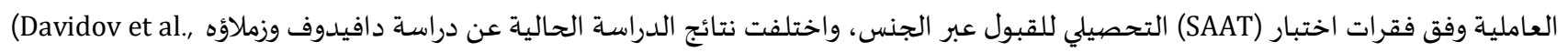
(2015 لقياسات الاتجاهات نحو الهجرة في المسح الاجتماعي الأوروبي: باستخدام اللاتغير الدقيق الكلاسيكي بمقابل لاتغير القياس التقريبي، حيث تم

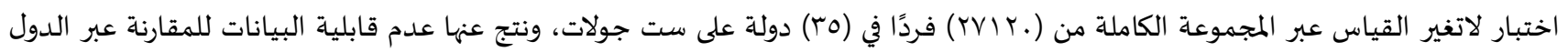

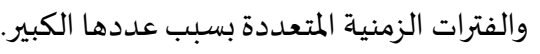

التوصيات والمقترحات:

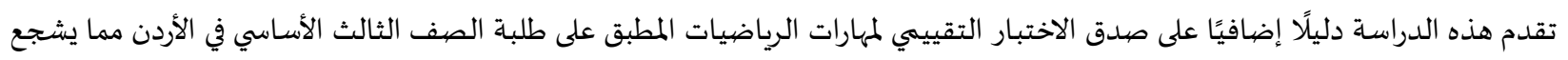

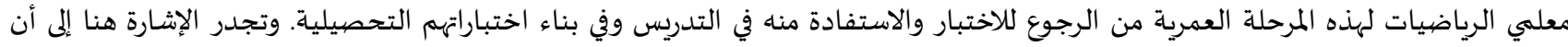

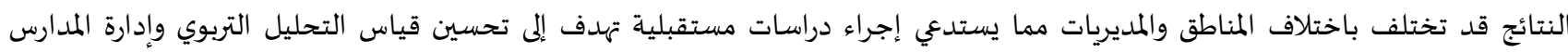
والصفوف، ومراجعة إجراءات تطبيق الاختبار.

ا. التقي، احمد محمد عيسى. (Y (99). "اللاتغير في تقدير معالم الأفراد ودرجات صعوبة أسئلة المقال من خلال نموذجي التقدير الجزئي وسلم

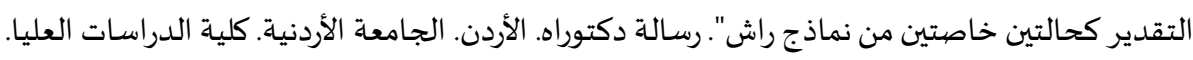

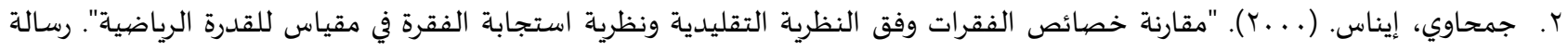
ماجستير.جامعة اليرموك. الأردن.

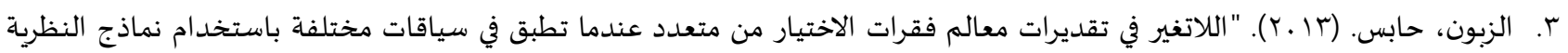

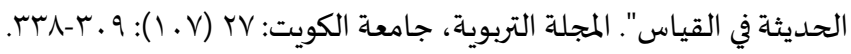


ع. الشريفن، نضال كمال. (9 ا. ()." أثر نموذج نظربة الاستجابة للفقرة ذات الاستجابة المتعددة التدربج على دقة تقدير القدرات للأفراد

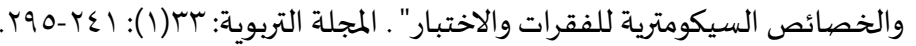

0. علام، صلاح الدين. (0. . . ). "نماذج الاستجابة للمفردات الاختيارية أحادية البعد ومتعددة الأبعاد وتطبيقاتها في القياس النفسي والتربوي". الطبعة الأولى. القاهرة. دار الفكر العربي.

7 . محمد، محمد إبراهيم. (1ا ـ ب). "قياس اللاتغير العاملي للكمالية بالتحليل العاملي التوكيدي للمجموعات المتعددة". مجلة التربية وعلم النفس:

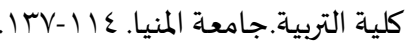

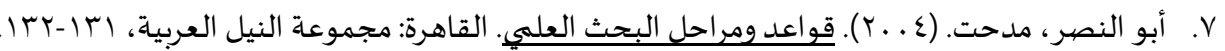

ثانياً: المراجع الأجنبية:

[1] Adam W. \& Gary J. (2004). "A Monte-Carlo Study of Confirmatory Factor Analytic Tests of Measurement Equivalence/ Invariance", Structural Equation Modeling, 11(1): 60-72. https://doi.org/10.1207/s15328007sem1101_5.

[2] Bentler, P. M. (1990). “Comparative fit indexes in structural models”. Psychological Bulletin, 107(2): 238-246. https://doi.org/10.1037/0033-2909.107.2.238.

[3] Billiet, J. (2003). “Cross-cultural equivalence with structural equation modeling”. In J.A. Harkness, F. J. R. Van de Vijver, and P. P. Mohler (Eds.), Cross-cultural survey methods (pp. 247-264). New York, NY: John Wiley.

[4] Byrne, B. \& Watkins, D. (2003). "The issue of measurement invariance revisited". Journal of Cross-Cultural Psychology, 34(2): 155-175. https://doi.org/10.1177/0022022102250225.

[5] Cangur, S. \& Ercan, L. (2015). "Comparison of Model Fit Indices Used in Structural Equation Modeling Under Multivariate Normality”. Journal of Modern Applied Statistical Methods, 14 (1): 152-167. DOI: 10.22237/jmasm/1430453580.

[6] Chen, F. F. (2007). "Sensitivity of goodness of fit indexes to lack of measurement invariance". Structural Equation Modeling, 14(3): 464-504. https://doi.org/10.1080/10705510701301834.

[7] Dimitrov, M. (2013). "GAT-Verbal: Testing for Dimensionality and Validation of Factorial Structure". Technical Report TR011-2013. National Center for Assessment in Higher Education.

[8] Embretson, S. E. \& Reise, S. P. (2000). "Item Response Theory for Psychologists", New Jersey: Lawrence Erlbaum Associates, Publishers.

[9] Finch, H. (2014). "Measurement Invariance. In Michalos", A.C, (ed.), Encyclopedia of Quality of Life and Well-Being Research, (pp 3909-3912). Springer Science+Business Media.

[10] Gadelrad, H. (2004). "The effect of model misspecification on goodness-of-fit indices for Structural equation modeling". Unpublished PhD, Wayne State University, Detroit, MI.

[11] George, A. \& Irini, M. (2002). "Latent Variable \& Latent Structure Models”, Lawrence Erlbaum Association, Inc, USA.

[12] Hair, J., Anderson, R., Tatham, R. \& Black, W. (1995). "Multivariate Data Analysis with Reading”, Fourth Edition, New Jersey. Prentice-Hall, Inc.

[13] Hambleton, R.K. \& Swaminathan, H. (1985). "Item Response Theory: Principles and applications", Boston MA: KluwerNyjhoff.

[14] Hambleton, R.K. and Swaminathan, H. \& Rogers, H.J. (1991). "Fundamentals of Item Response Theory: International Educational and Professional", Publisher Newbury park.

[15] Hu, L. and Bentler, P. (1999). "Evaluating model fit. In R. H. Hoyle (Ed.)", Structural equation modeling: Concepts, issues, and applications (pp. 76-99). Thous and Oaks, CA: Sage.

[16] Jöreskog, K. (1969). "A general approach to confirmatory maximum likelihood factor analysis". Psychometrical, 34(2): 183-202. https://doi.org/10.1007/bf02289343.

[17] Jöreskog, K. (1971). "Simulaneous factor analysis in several populations". Psychometrical, 36(4): 409-426. https://doi.org/10.1007/bf02291366.

[18] Lattin, J., Carrol, J. \& Green, P. (2003). “Analyzing multivariate data”. Brooks/Cole, Pacific Grove, CA. Thompson Learning.

[19] Little, D.T, (1997). "Mean and Covariance Structures (MACS) Analyses of Cross-Cultural Data: Practical and Theoretical Issues". Multivariate Behavioral research, 32(1): 53-76. https://doi.org/10.1207/s15327906mbr3201_3.

[20] Lord, F. (1980). “Application of Item Resonse to practical testing problems”. Hillsdale, NJ, Evbaum.

[21] MacCallum RC, Roznowski M \& Necowitz LB. (1992). "Model modifications in covariance structure analysis: the problem of capitalization on chance". Psychol. Bull. 111(3): 490- 504. https://doi.org/10.1037/0033-2909.111.3.490. 
[22] McArdle, J.J., (1996). “Current Directions in Structural Factor Analysis”. Current Directions in Psychological Science, 5(1) 11-18. https://doi.org/10.1111/1467-8721.ep10772681.

[23] Millsap, R. E. (2011). “Statistical approaches to measurement invariance”. Florence, KY: Routledge.

[24] Muthén, B., Christoffersson, A., (1981). "Simultaneous factor analysis of dichotomous variables in several groups". Psychometrika, 46: 407-419. https://doi.org/10.1007/BF02293798.

[25] Sörbom, D. (1989). "Model modification”. Psychometrika, 54: 371-384.

[26] Tucker, L. R., \& Lewis, C. (1973). "A reliability coefficient for maximum likelihood factor analysis". Psychometrika, 38(1): 1-10. https://doi.org/10.1007/bf02291170.

[27] Vendenberg, R. \& Lance, C. (2000). "A review and synthesis of the measurement invariance Literature: suggestions, practices, and recommendations for organizational research". Organizational research Methods, 3(1): 4-69. doi:10.1177/109442810031002. 


$$
\text { المجلة الدولية للدراسـات التربوية والنفسية }
$$

International Journal of Educational \& Psychological Studies (EPS)

\title{
The invariance detected in the assessment test for mathematics skills for the third basic class students through the directorates of education in Jordan
}

\author{
Areej Hasan Alsaid \\ Bani Obaid Directorate of Education, Irbid, Jordan \\ areej_alsaid@yahoo.com
}

Nedal Kamal Alshreefen

Department of Counseling \& Educational Psychology, Faculty of Education, Yarmouk University, Jordan

Received : 16/3/2020 Revised : 5/4/2020 Accepted : 28/4/2020 DOI : https://doi.org/10.31559/EPS2021.9.1.8

Abstract: This study aimed to detect the Invariance in the test for the third basic grade in Jordan through directorates of education (numbering 45 directorates). To achieve this, the descriptive analytical method was used in analyzing the results of students on the test who participated for the 2017/2018 academic year, specifically the responses of (37272) boys and (36176) girls were analyzed on (25) multiple choice test items, and were analyzed Paragraph data using two methods of confirmatory factor analysis (CFA) and multigroup factor analysis (MGCFA) through the statistical program (Mplus v8.4), and to judge the appropriateness of the global construction of the test five good-matching indicators were used: $\left(\chi^{2}\right)$, (CFI), (RMSEA), (SRMR), (TLI). The results showed the suitability of the proposed model with its seven skills for the content of the test, and the results also showed the presence of configuring, metric, and scalar invariance across (36) from (45) directorates.

Keywords: Invariance of measurement; Math skills assessment test; Good-match indicators; Confirmatory factor analysis

\section{References:}

[1] 'lam, Slah Aldyn. (2005). "Nmadj Alastjabh Llmfrdat Alakhtyaryh Ahadyh Alb'd Wmt'ddh Alab'ad Wttbyqatha Fy Alqyas Alnfsy Waltrbwy". Altb'h Alawla. Alqahrh. Dar Alfkr Al'rby.

[2] Jmhawy, Eynas. (2000). "Mqarnh Khsa's Alfqrat Wfq Alnzryh Altqlydyh Wnzryh Astjabh Alfqrh Fy Mqyas Llqdrh Alryadyh". Rsalt Majstyr. Jam't Alyrmwk. Alardn.

[3] Mhmd, Mhmd Ebrahym. (2011). "Qyas Allatghyr Al'amly Llkmalyh Balthlyl Al'amly Altwkydy Llmjmw'at Almt'ddh". Mjlt Altrbyh W'Im Alnfs: Klyt Altrbyh. Jam't Almnya. 114-137.

[4] Abw Alnsr, Mdht. (2004). Qwa'd Wmrahl Albhth Al'lmy. Alqahrh: Mjmw'h Alnyl Al'rbyh, 131-132.

[5] Alshryfyn, Ndal Kmal. (2019)." Athr Nmwdj Nzryh Alastjabh Llfqrh Dat Alastjabh Almt'ddh Altdryj 'la Dqh Tqdyr Alqdrat Llafrad Walkhsa's Alsykwmtryh Llfqrat Walakhtbar". Almjlh Altrbwyh: 33(1): 241-295.

[6] Altqy, Ahmd Mhmd 'ysa. (1992). "Allatghyr Fy Tqdyr M'alm Alafrad Wdrjat S'wbh As'lh Almqal Mn Khlal Nmwdjy Altqdyr Aljz'y Wslm Altqdyr Khaltyn Khastyn Mn Nmadj Rash". Rsalt Dktwrah. Alardn. Aljam'h Alardnyh. Klyt Aldrasat Al'lya.

[7] Alzbwn, Habs. (2013). "Allatghyr Fy Tqdyrat M'alm Fqrat Alakhtyar Mn Mt'dd 'ndma Ttbq Fy Syaqat Mkhtlfh Bastkhdam Nmadj Alnzryh Alhdythh Fy Alqyas". Almjlh Altrbwyh, Jam't Alkwyt: 27 (107): 309-338. 